
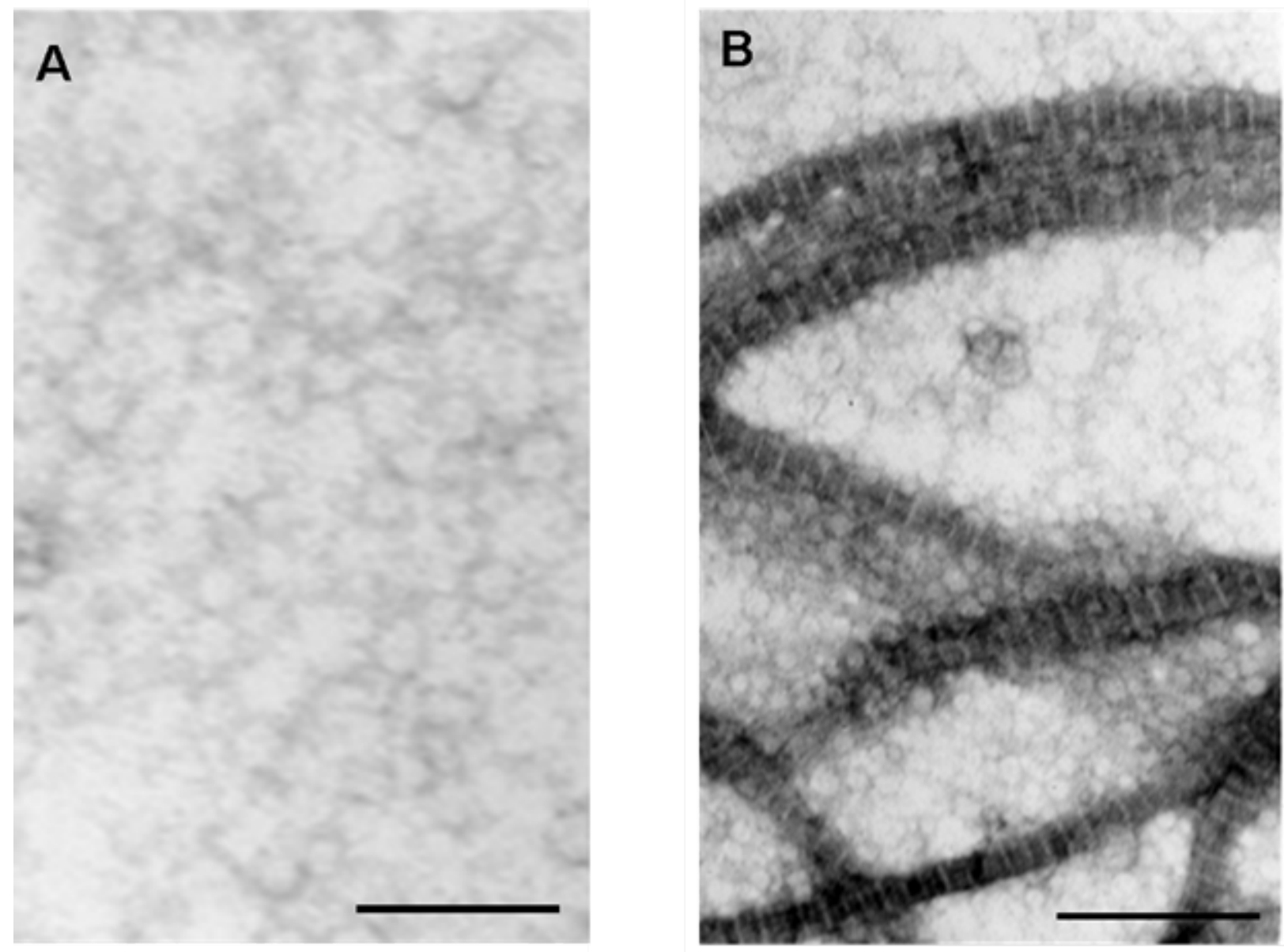

Fig. 1 
A
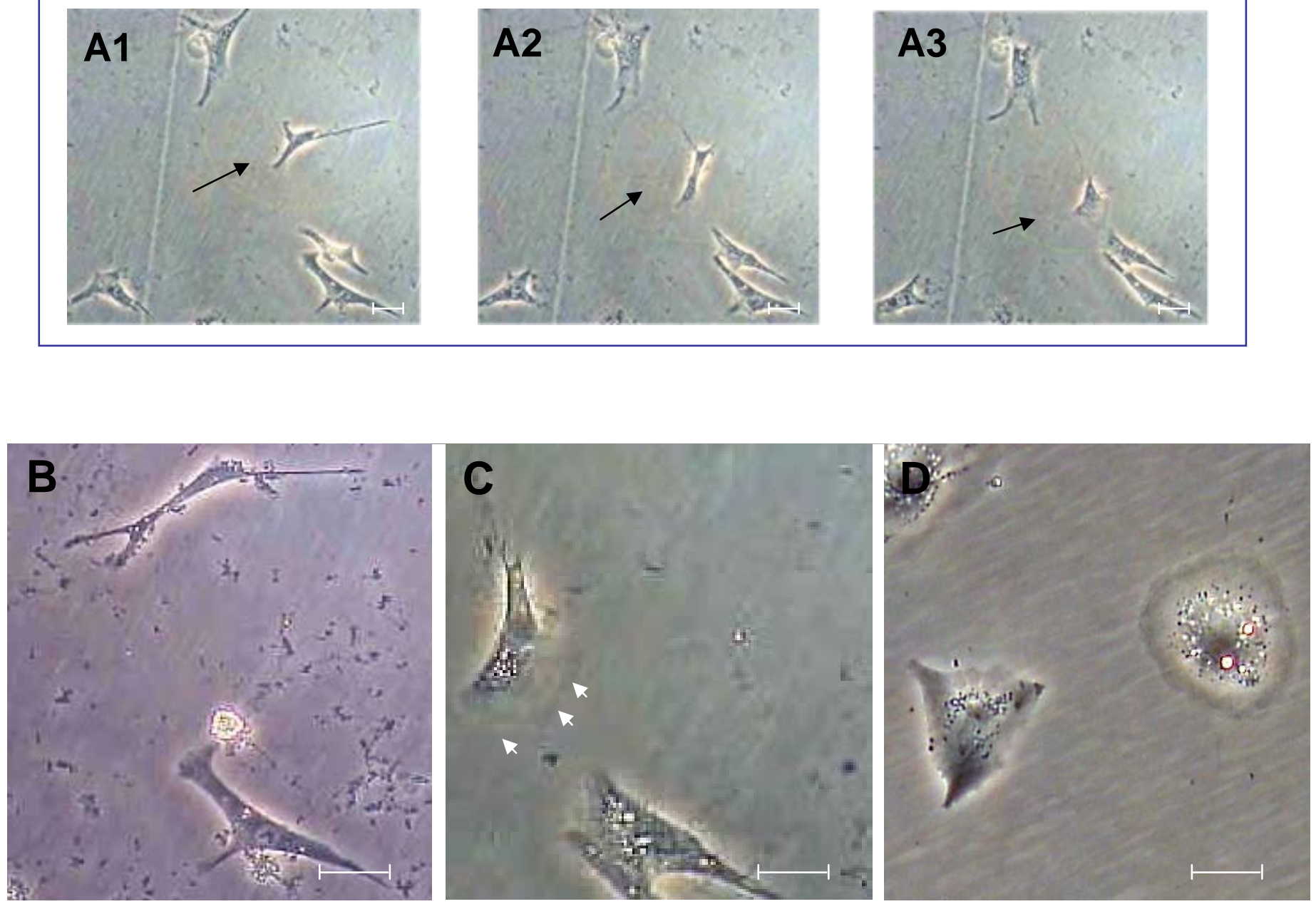

Fig. 2 

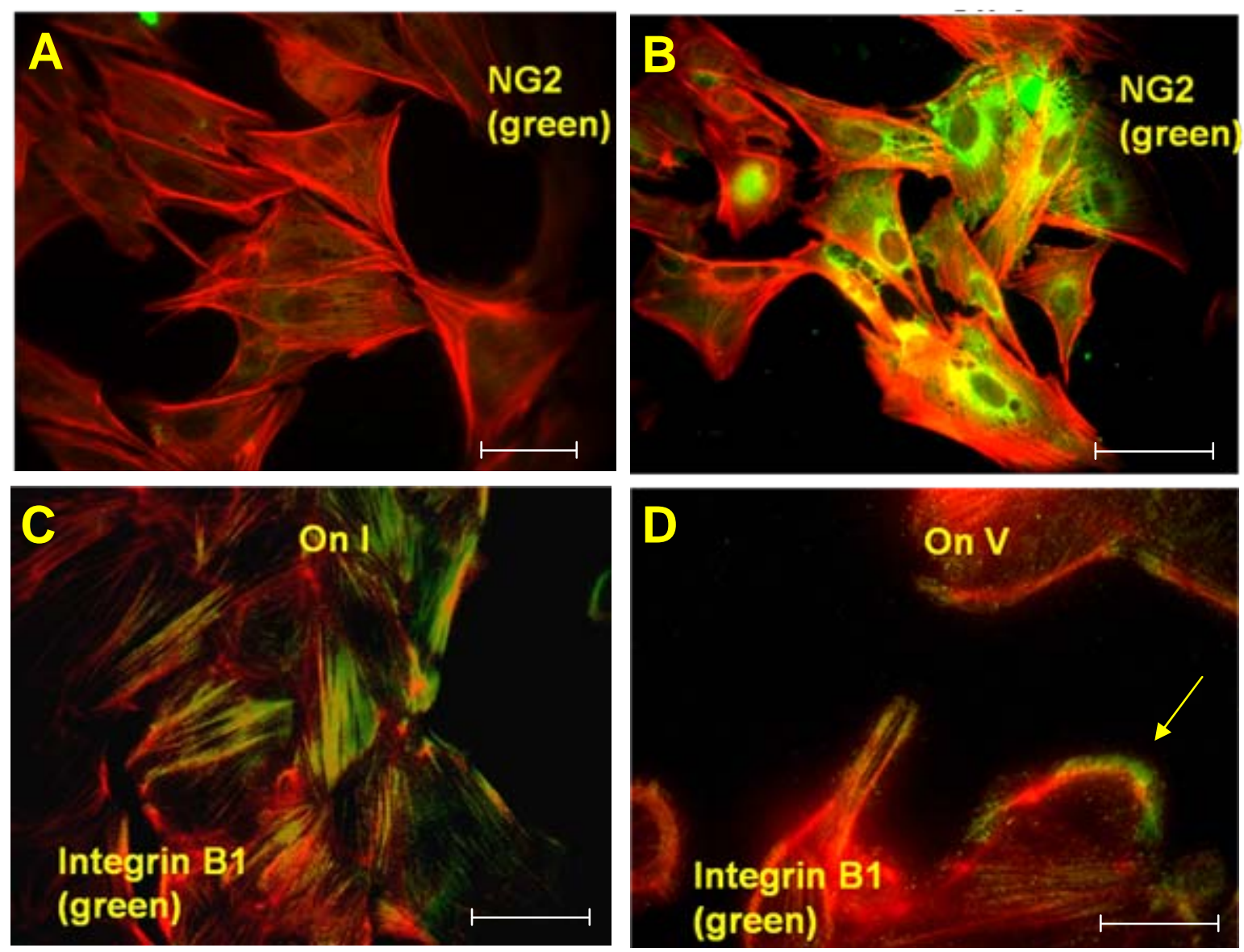

Fig. 3 

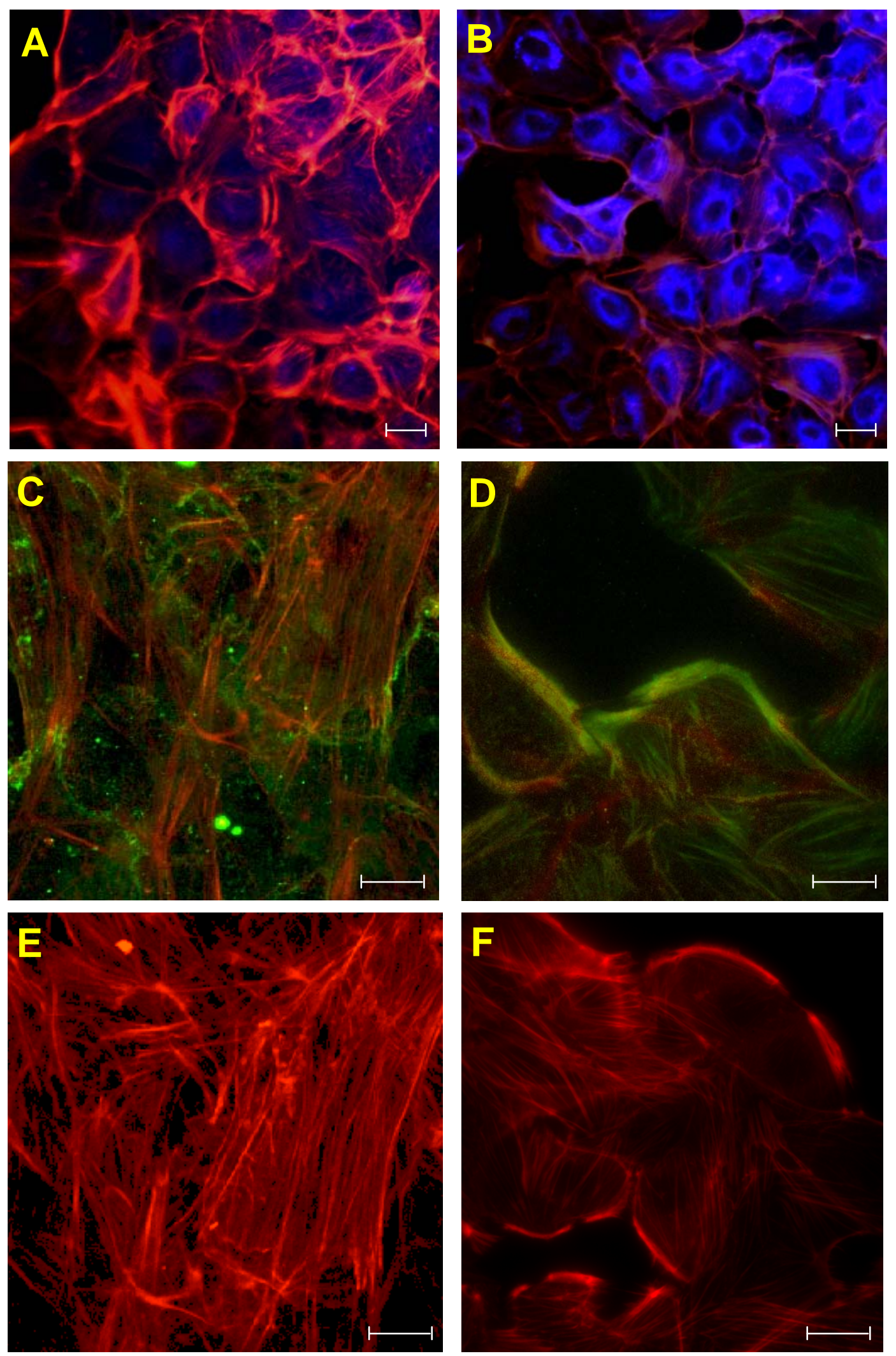

Fig. 4 


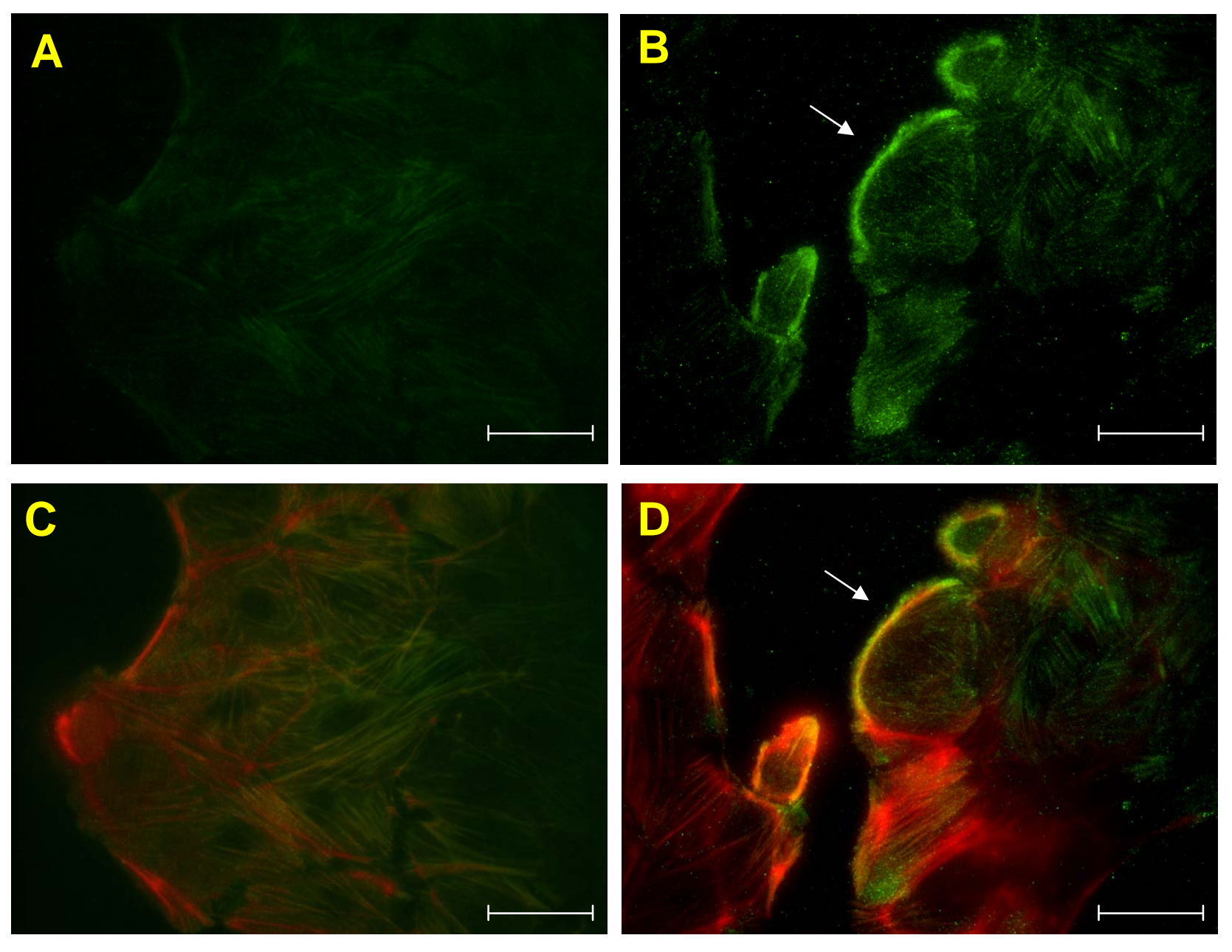

Fig. 5 


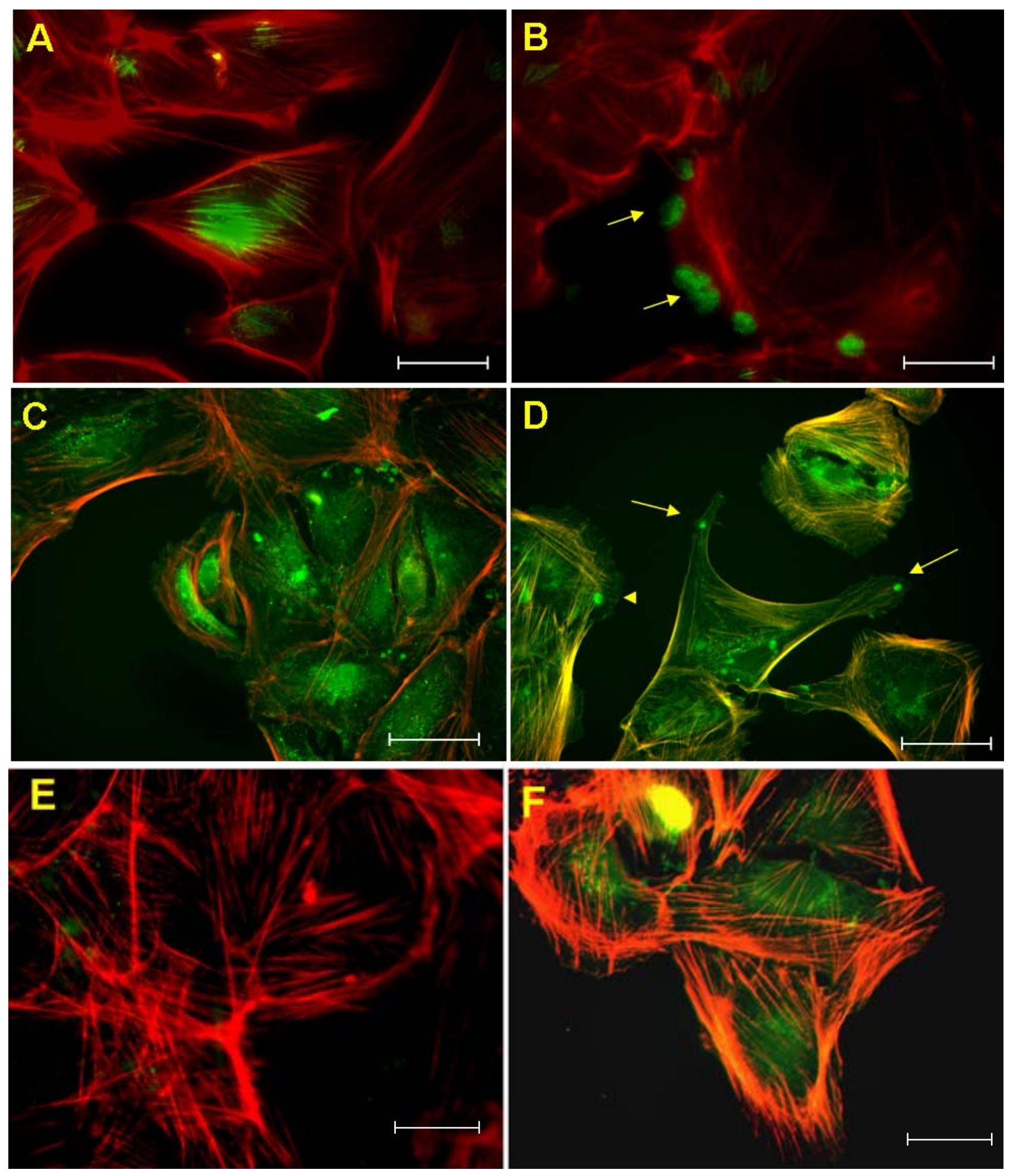

Fig. 6 

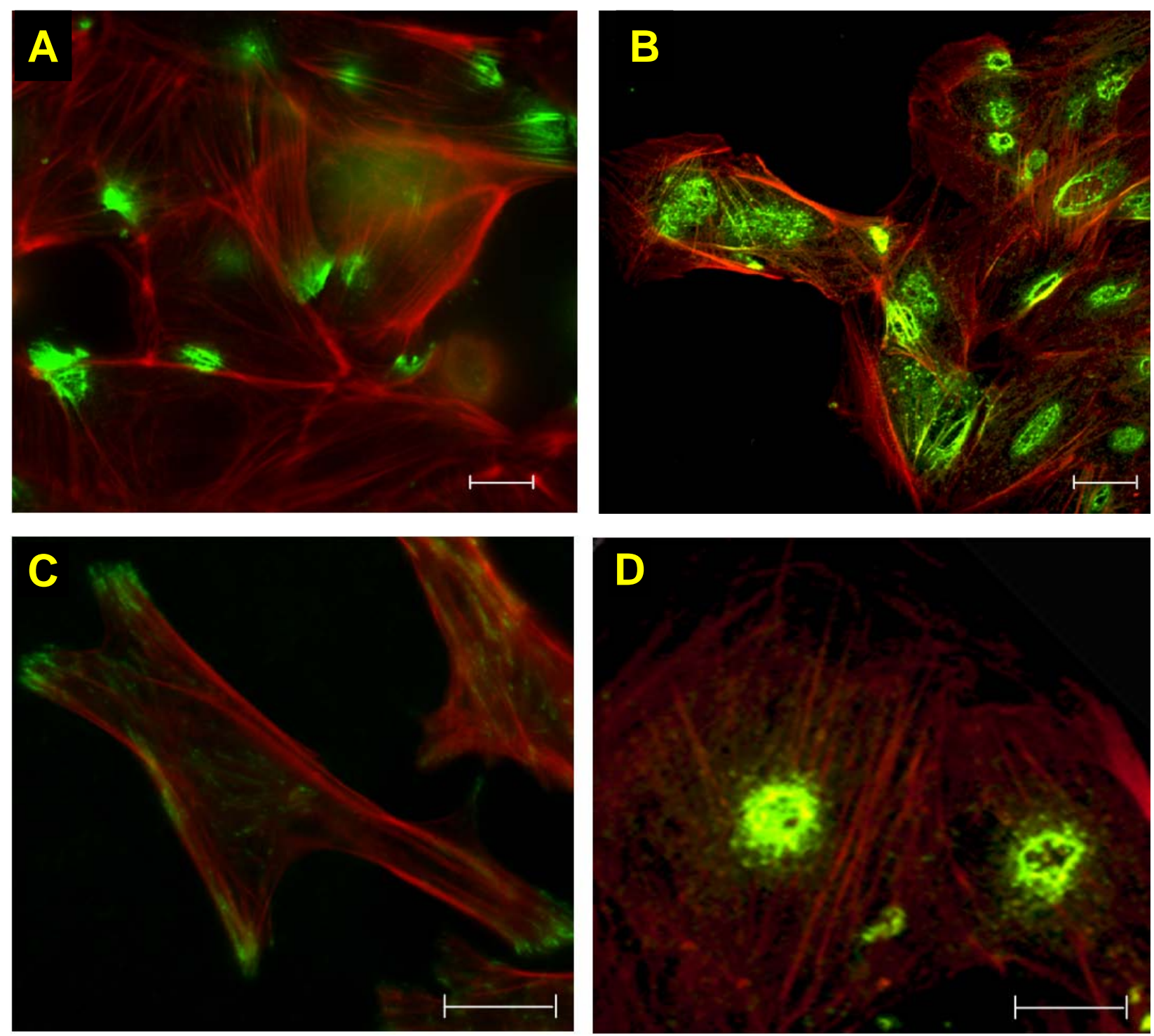

D

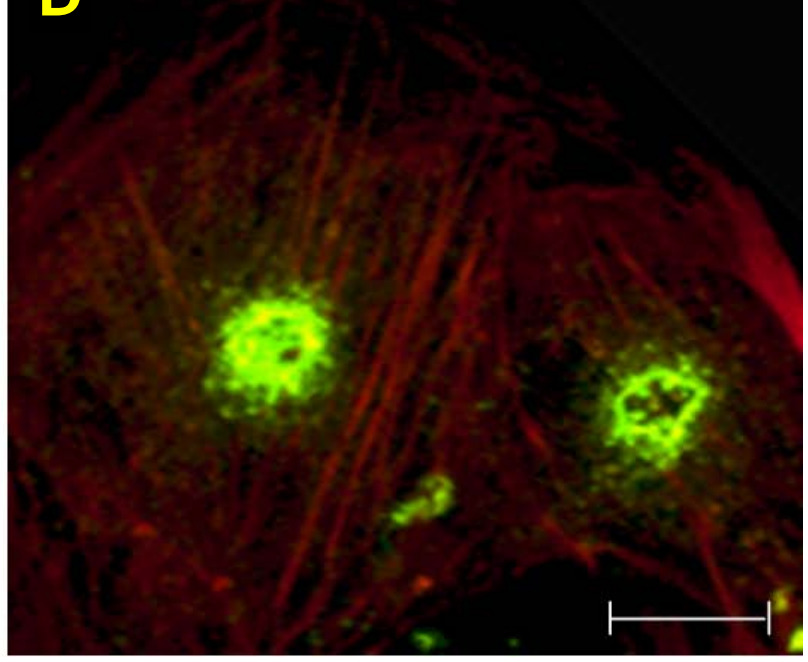

Fig. 7 

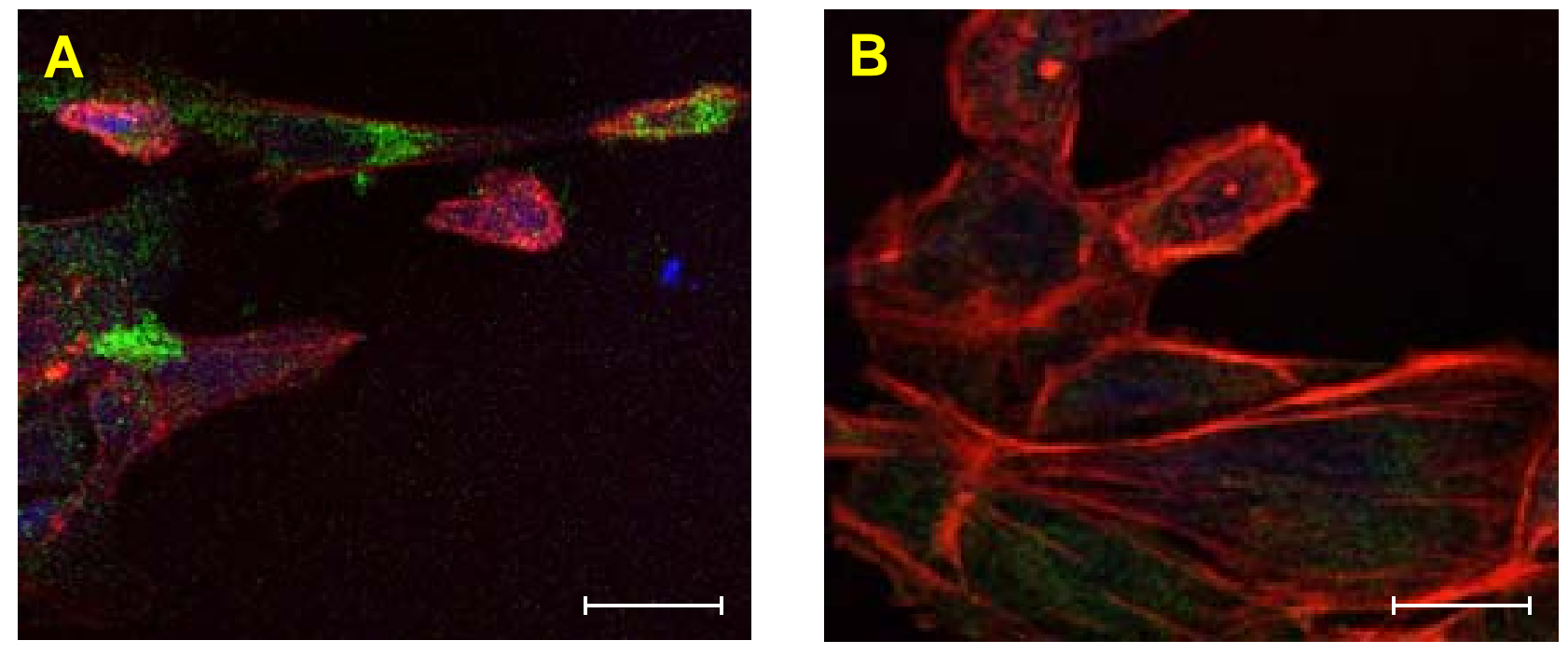

C

D

sosts

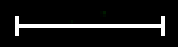

E

F

Fig. 8 

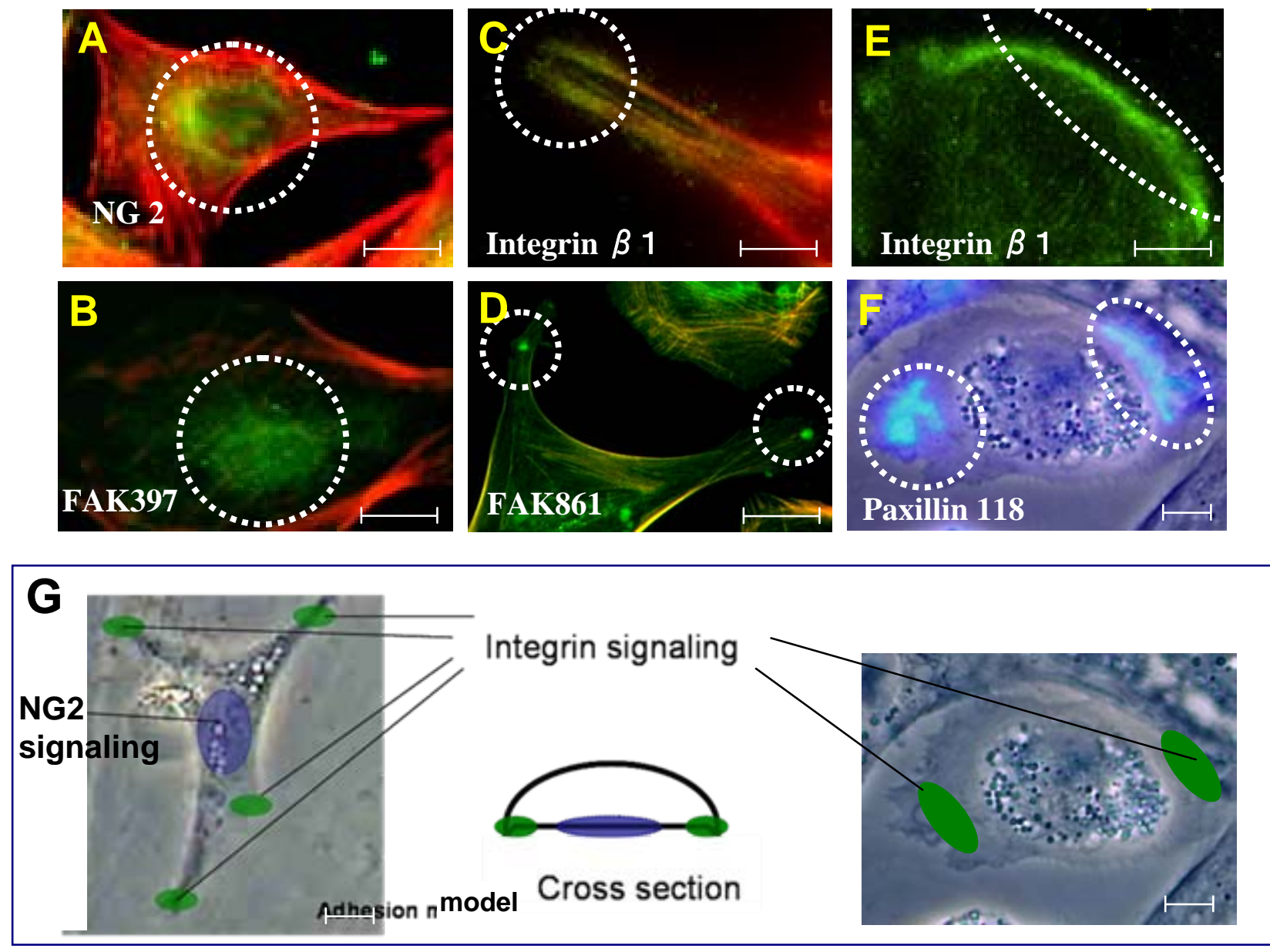

H

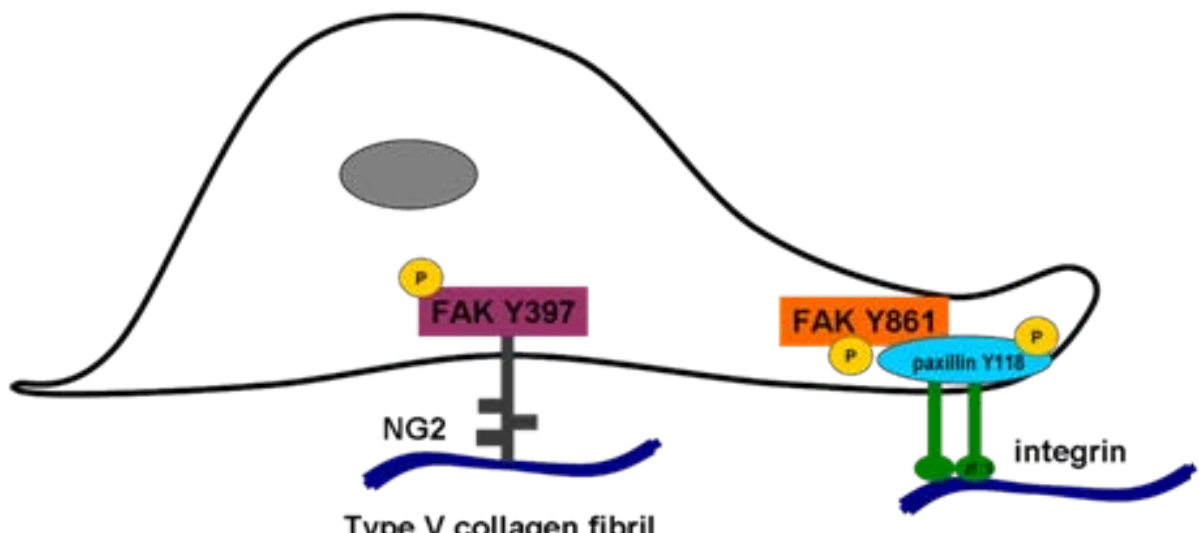

Type V collagen fibril

Fig. 9 


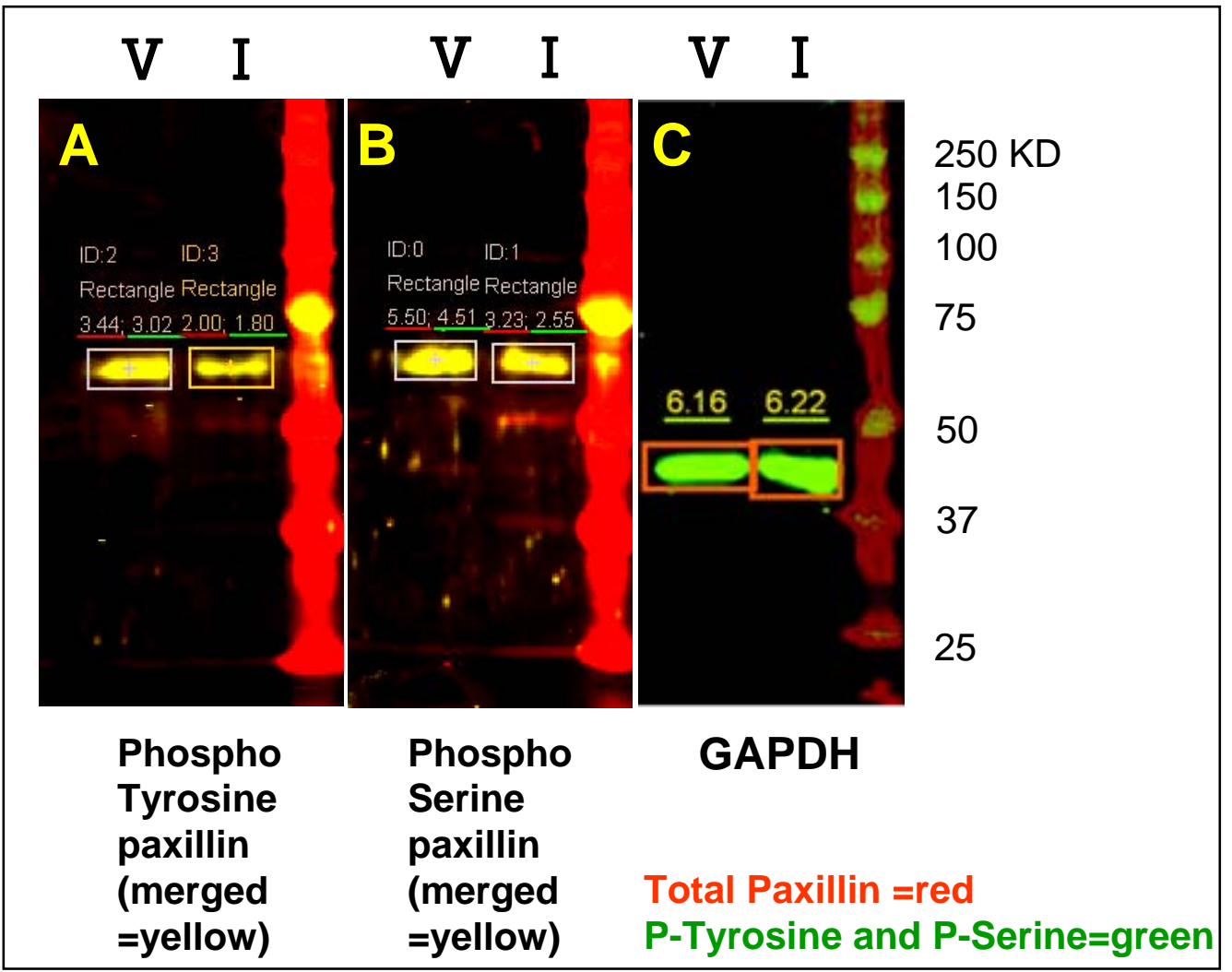

D 4days 7days 20days

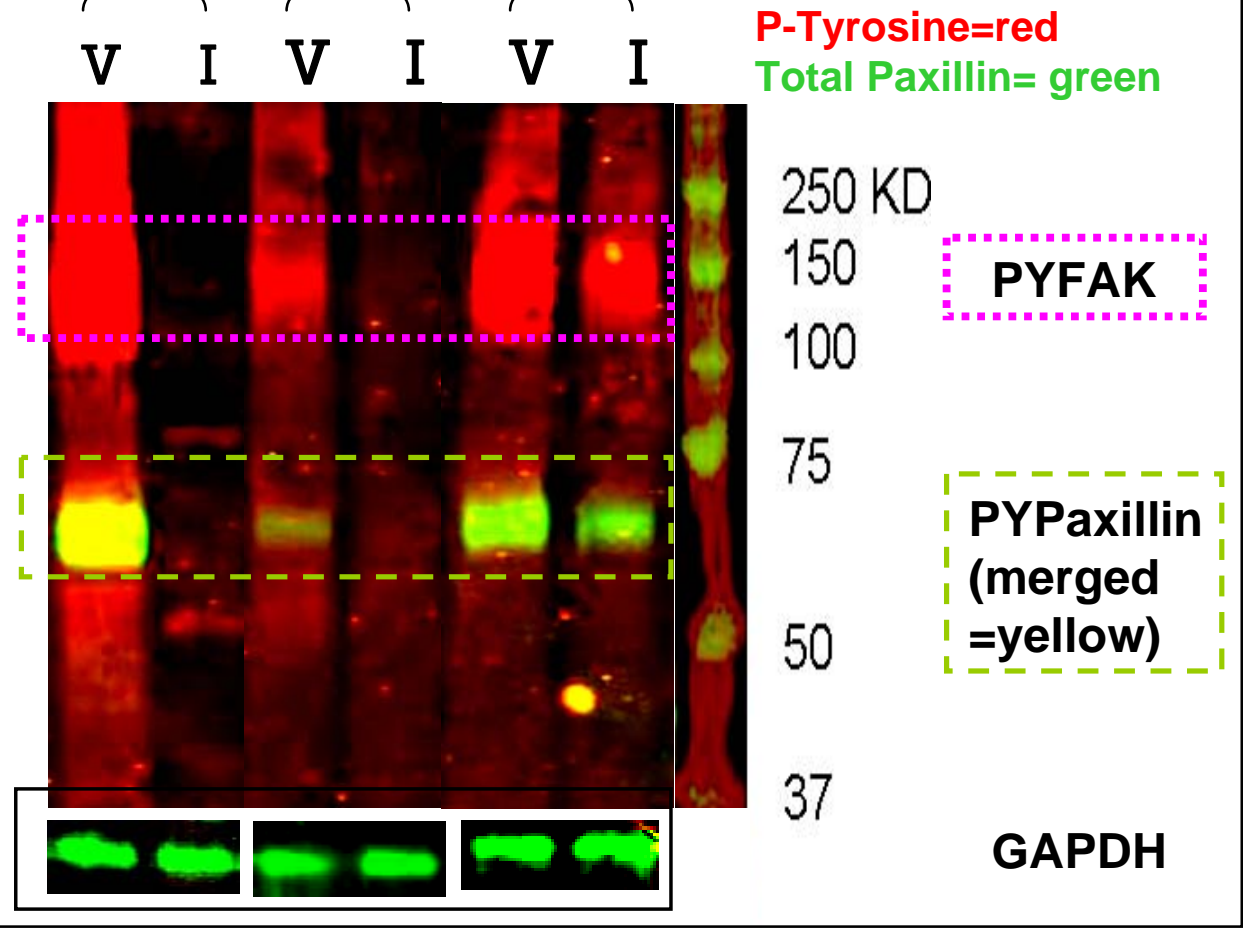

Fig. 10 


\section{Table. 1}

Intensity changes of phosphorylated adaptor proteins in cells cultured on collagen $V$ fibrils at time intervals

\begin{tabular}{|c|c|c|c|c|c|c|}
\hline & $3 d$ & $4 d$ & $7 d$ & $10 d$ & $20 d$ & $30 d$ \\
\hline pY Paxillin & ++ & ++ & $*$ & ND & ++ & ND \\
\hline non pY paxillin & -- & -- & + & ND & + & ND \\
\hline FAK pY861 & ND & ++ & ND & ++ & ND & ++ \\
\hline FAK pY397 & ND & $*$ & ND & -- & ND & $*$ \\
\hline
\end{tabular}

$++\quad$ Band with significant high intensity in phosphoprotein of cells cultured on Col V fibrils as compared with Col I

$+\quad$ Band with high intensity of phosphoprotein of cells cultured on Col V fibrilsAs compared with Col I

- - Band with significant low intensity in phosphoprotein of cells cultured on Col V fibrils as compared with Col I

* $\quad$ Band with the same intensity in phosphoprotein of cells cultured Col $\mathrm{V}$ fibrils as that on Col I

ND Not detected 